of industry partnerships. These centres receive generous funding from the government the CICCSE receives around 50 million yuan (US\$7.5 million) each year - as well as flexibility in the selection of research projects and the recruitment of scientists (unusual freedoms within government programmes in China, according to Chen).

Cong Cao, a science-policy analyst at the University of Nottingham in Ningbo, says that the "new normal" of the Chinese economy, referring to slowed growth, means that the government has had to look to science and technology, with programmes such as the $\mathrm{CICs}$, as the way to restore dynamism.

\section{FORMING PARTNERSHIPS}

In 2007, the Progress of Science and Technology Law was passed. The law, which is often referred to as the Chinese Bayh-Dole Act - a celebrated 1980s US patent-rights law credited with accelerating US industrial innovation enables the intellectual property generated by government-funded research to be commercialized by the research group that does the investigation. The law has made it much easier for research institutions such as Chen's to benefit from the work their researchers are doing. In the seven years after the enactment of the law, the number of domestic patents awarded to Chinese researchers increased more than five-fold.

The legislation has also made research partnerships between universities and industry more attractive for both sides.

Over the past four years in particular, Cao says, the Chinese government has introduced a range of policies "to emphasize innovation and reform of China's science and technology system to make it better and quicker to respond to demand from the economy". This includes the launch of the thirteenth Five Year Plan in 2015, which put innovation in science and technology at the centre of China's development.

And following Premier Li Keqiang's annual address to the National People's Congress in March, there have been further efforts to encourage co-operation between science and industry. Speaking to the 2,943 delegates in the Great Hall of the People in Beijing, Li echoed what President Xi Jinping had outlined in the Five Year Plan, using the word 'innovation' more than 50 times. The speech also included promises of new national science and technology programmes and science centres. By 2020, said $\mathrm{Li}$, science and technology will account for $60 \%$ of the nation's economic growth.

"We will implement the strategy of innovation-driven development, see that science and technology become more deeply embedded in the economy, and improve the overall quality and competitiveness of the real economy," Li said.

The government promised tax deductions for companies undertaking research and development; and, since the speech, it

has begun efforts to substantially reduce the notorious red tape associated with government funding for research and to increase the income that Chinese scientists can receive for working on government-funded projects.

Back at the CICCSE, Chen and his colleagues have secured a Chinese patent on their battery technology, one of 339 patents awarded to the centre's projects up until the end of 2015. They are now working on adjustments to scale the technology up and overcome the need for a pure $\mathrm{CO}_{2}$ environment. Chen expects to have an improved version in production in about two years. Chen's group is also collaborating with Tianjin-based Li-ion battery developer Lishen and with electronics

\section{"The \\ assessment \\ of CICs \\ should focus}

on how well the expected objectives are achieved." manufacturer Samsung, on improvements to Liion batteries for devices such as electric cars.

The CICCSE, like other centres, works with industry in three ways: companies are founding members of the centres and are represented on the board, Chinese petroleum giant Sinopec and the Tianjin Bohai Chemical Industry Group both have representatives on the CICCSE board, for example; the centre's researchers do joint research with industry on major national issues; and the companies fund research projects.

Sinopec is currently funding research to improve hydrogen production for use in fuel processing and the chemical industry. The project is using nanofabrication techniques to increase the stability of nickel-based catalysts, which are used in the methane-steam reforming process to create hydrogen. The greater stability increases the efficiency so that alternative fuels such as ethanol can be used. The hydrogen can then be used to refine petroleum,

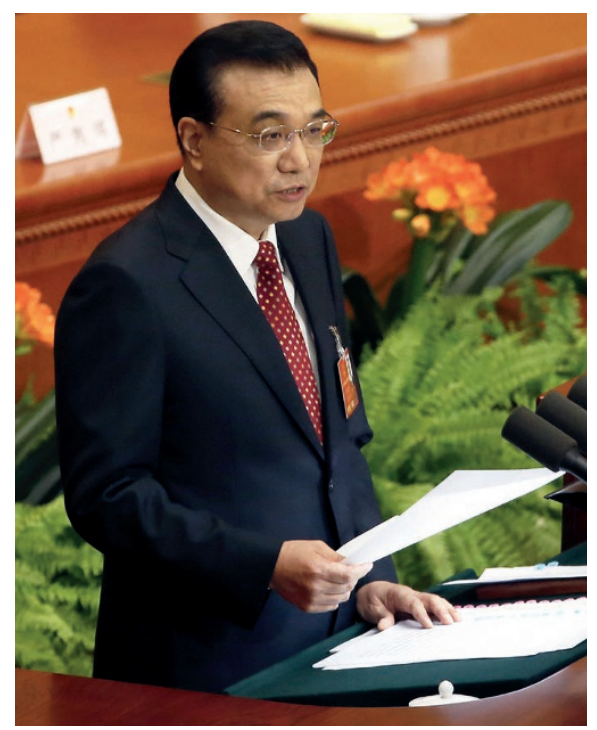

Premier Li Keqiang used 'innovation' 50 times in his address to the National People's Congress. particularly heavier crude oils. When complete, Sinopec will implement the new technology in a number of its fuel-processing plants.

Yao says that another project has already seen crystallization technology developed by CICCSE researchers adopted by the pharmaceutical industry and increase revenue by nearly 4 billion yuan.

\section{UNCERTAIN FUTURE}

Despite such success stories, there is concern that science is not yet playing a part in the Chinese economy in the way that Hu Jintao had hoped. There have been lots of the incremental improvements, but not yet an innovation that changes the market. Initiatives aimed at encouraging more innovation are beginning to show signs of success. The government says that there are now at least 81 million people in China who work in science and technology. But researchers and analysts say there is no guarantee that even successful programmes will continue without substantial change.

Cong says that the nature of Chinese science policy means that change is never far away. Based on Li's statements at the 2016 National People's Congress, the 38 CICs are unlikely to be immune. The Ministry of Education may already be trying to put the premier's words into practice, says Cong. This means that "there could soon be different programmes put into place", he says.

For now the CICCSE is still receiving strong support from the ministry, which is responsible for the CIC programme. But Yao agrees that there is a risk that new policies, such as those put forward at this year's National People's Congress, and President Xi Jinping's efforts to create his own policy legacy, could mean the programme is superseded or significantly altered in coming years. This may not signal an end to the support for existing centres, but it could mean the central government introduces an updated version, perhaps rebranding the $\mathrm{CICs}$ as national laboratories.

"The assessment of CICs should focus on how well the expected objectives are achieved; in other words, how well the centres address the major issues in science, technology and economic development," says Yao. Yao is confident about CICCSE's future. By the end of 2015 , he points out, the centres' researchers boasted not only hundreds of patents but also 295 contributions to high-quality journals.

The move towards better collaboration between academics and industry in the hope of creating stronger links between science and economic and social needs has been occurring around the world over the past decade. After less than five years, it is still early days for China's experiment. But signs indicate that the country is on a promising path.

Annabel McGilvray is a freelance science writer based in Sydney, Australia. 